\title{
The 1000 Canadian faces of systemic lupus erythematosus: effect of ethnicity on baseline pediatric data
}

\author{
Deborah M Levy ${ }^{7 *}$, Earl D Silverman², Lori B Tucker ${ }^{1}$, Gaelle Chédeville ${ }^{5}$, Adam Huber ${ }^{4}$, Janet E Pope ${ }^{6}$, \\ Christine A Peschken $^{8}$, CaNIOS Investigators ${ }^{3}$
}

From 2011 Pediatric Rheumatology Symposium sponsored by the American College of Rheumatology Miami, FL, USA. 2-5 June 2011

\section{Purpose}

To determine the influence of ethnicity and sociodemographic factors on disease presentation, manifestations, disease activity, and disease outcomes, using baseline data from the pediatric arm of the 1000 Canadian Faces of Lupus Study, a multicenter, prospective study of the Canadian Lupus population.

\section{Methods}

Childhood-onset SLE ( $<18^{\text {th }}$ birthday) patients at four pediatric centers (Halifax, Montreal, Toronto and Vancouver). Collected data included sociodemographics, disease manifestations, current/past medications, laboratory measures and multiple disease measures. The Child Health Questionnaire (CHQ), measuring multiple domains of health status was administered. For analysis, patients were categorized by their primary self-selected ethnic category.

\section{Results}

Between November 2005 and February 2009, 213 cSLE patients were enrolled. The number of patients enrolled at each site mirrored the size of the clinical centre: Toronto 134 (63\%), Vancouver 54 (25\%), Montreal 17 (8\%), and Halifax 8 (4\%). There were 176 (83\%) females, mean age at diagnosis was $12.5 \pm 0.3$ years, mean disease duration was $2.5 \pm 2.7$ years, and 175 patients $(82 \%)$ were born in Canada. Demographic data were similar across the geographic sites, except for a longer disease duration in Vancouver $(3.9 \pm 3.6$ years, $\mathrm{p}<.001)$. Primary self-reported race/ethnicity data was available for 191 patients: White (31\%), Asian (30\%), South Asian (15\%), Black (10\%),

${ }^{7}$ The Hospital for Sick Children, Toronto, ON, Canada

Full list of author information is available at the end of the article
Latino/Hispanic (4\%), Aboriginal (4\%) and Arab/Middle Eastern (3\%). Because of low numbers, the Latino/Hispanic and Arab/Middle Eastern groups were excluded from the analysis. Ethnic distribution across the centers differed $(\mathrm{p}<.001)$, reflecting known differences in the urban populations. The distribution of household income, and prescription drug plan coverage did not differ across ethnicities, however, fewer Asians (64\%) had dental insurance coverage as compared to White (88\%) and Aboriginal $(100 \%)$ patients $(\mathrm{p}<.01)$. Missed school days did not differ by ethnicity, although $26 \%$ of the entire cohort reported missing on average 6 days per month. CHQ scores were lower in 7 of 10 domains in white patients vs. non-white ethnicities ( $\mathrm{p}<.05$ for each). Autoantibodies and SLE classification criteria present at any time that differed by ethnicity are listed in table 1.

Medications were prescribed equally across ethnicities; most patients were taking prednisone (75\%), hydroxychloroquine (84\%), and 56\% required additional immunosuppression (azathioprine, methotrexate, mycophenolate mofetil or cyclophosphamide). Disease measures were similar across ethnicities, overall SLEDAI was $3.1 \pm 4.2$, SLAM 3.4 \pm 3.7 ; SDI median 0.3 (range 0-5), and physician global VAS was $15 \pm 23$ (range 0-99).

\section{Conclusion}

Canadian cSLE patients reflect our multi-ethnic population, with observed differences in disease manifestations, antibody profiles and health status by ethnicity.

\section{Disclosure}

Deborah M. Levy: None; Earl D. Silverman: None; Lori B. Tucker: None; Gaelle Chédeville: None; Adam Huber:

(C) 2012 Levy et al; licensee BioMed Central Ltd. This is an Open Access article distributed under the terms of the Creative Commons 
Table 1 Classification criteria by ethnicity

\begin{tabular}{|c|c|c|c|c|c|c|c|}
\hline Criterion \%present & Total $(n=191)$ & Aboriginal $(n=9)$ & Asian $(n=63)$ & South Asian $(n=32)$ & Black $(n=22)$ & White $(n=65)$ & $\mathrm{p}$-value \\
\hline Malar rash & 65 & 33 & 65 & 66 & 36 & 78 & $<0.05$ \\
\hline Arthritis & 62 & 78 & 46 & 72 & 59 & 71 & $<0.05$ \\
\hline Serorsitis & 18 & 44 & 16 & 16 & 41 & 11 & $<0.05$ \\
\hline Renal & 36 & 33 & 51 & 28 & 59 & 22 & $<0.01$ \\
\hline Immunologic & 81 & 100 & 87 & 97 & 82 & 65 & $<0.001$ \\
\hline dsDNA & 66 & 56 & 75 & 81 & 73 & 49 & $<0.01$ \\
\hline Anti-Sm & 32 & 56 & 43 & 22 & 41 & 20 & $<0.05$ \\
\hline aPL (ACL or $\mathrm{LAC}$ ) & 47 & 33 & 49 & 53 & 55 & 42 & NS \\
\hline
\end{tabular}

None; Janet E. Pope: None; Christine A. Peschken:

None; CaNIOS Investigators: None.

\section{Author details}

${ }^{1}$ BC Childrens Hospital, Vancouver, BC, Canada. ${ }^{2}$ Hosp for Sick Children, Toronto, ON, Canada. ${ }^{3}$ Hospital for Sick Children, Toronto, ON, Canada. ${ }^{4}$ IWK Health Centre, Halifax, NS, Canada. ${ }^{5}$ Montreal Children's Hospital, Montreal, QC, Canada. ${ }^{6}$ St Joseph Health Care London, London, ON, Canada. ${ }^{7}$ The Hospital for Sick Children, Toronto, ON, Canada. ${ }^{8}$ University of Manitoba, Winnipeg, MB, Canada.

Published: 13 July 2012

- Convenient online submission

- Thorough peer review

- No space constraints or color figure charges

- Immediate publication on acceptance

- Inclusion in PubMed, CAS, Scopus and Google Scholar

- Research which is freely available for redistribution 